\title{
Hospital contextual factors affecting the implementation of health technologies: a systematic review
}

Adriano Grossi ${ }^{1 \dagger}$, Ilda Hoxhaj ${ }^{1 *+}$, Irene Gabutti ${ }^{2}$, Maria Lucia Specchia ${ }^{1,3}$, Americo Cicchetti ${ }^{2}$, Stefania Boccia ${ }^{1,4}$ and Chiara de Waure ${ }^{5}$

\begin{abstract}
Background: To keep a high quality of assistance it is important for hospitals to invest in health technologies (HTs) that have the potential of improving health outcomes. Even though guidance exists on how HTs should be introduced, used and dismissed, there is a surprising gap in literature concerning the awareness of hospitals in the actual utilization of HTs.

Methods: We performed a systematic literature review of qualitative and quantitative studies aimed at investigating hospital contextual factors that influence the actual utilization of HTs. PubMed, Scopus, Web of Science, Econlit and Ovid Medline electronic databases were searched to retrieve articles published in English and Italian from January 2000 to January 2019. The quality of the included articles was assessed using the Critical Appraisal Skills Programme checklist for qualitative studies, Newcastle-Ottawa Scale for the cross-sectional studies and the Mixed Methods Appraisal Tool for mixed method studies.

Results: We included 33 articles, which were of moderate to high methodological quality. The included articles mostly addressed the contextual factors that impact the implementation of information and communication technologies (ICTs). Overall, for all HTs, the hospital contextual factors were part of four categories: hospital infrastructure, human resource management, financial resources and leadership styles.

Conclusion: Our systematic review reported that the contextual factors influencing the HTs utilization at hospital level are mainly explored for ICTs. Several factors should be considered when planning the implementation of a new HTs at hospital level. A potential publication bias might be present in our work, since we included articles published only in English and Italian Language, from January 2000 to January 2019. There remains a gap in the literature on the facilitators and barriers influencing the implementation and concrete utilization of medical and surgical HTs, suggesting the need for further studies for a better understanding.
\end{abstract}

Keywords: Technology, Implementation, Hospital, Systematic review, Health technology assessment

\footnotetext{
*Correspondence: ilda.hoxhaj1@unicatt.it

${ }^{\dagger}$ Adriano Grossi and Ilda Hoxhaj contributed equally to this work.

'Section of Hygiene, University Department of Life Sciences and Public

Health, Università Cattolica del Sacro Cuore, Largo Francesco Vito, 1, 00168

Rome, Italy

Full list of author information is available at the end of the article
}

(C) The Author(s). 2021 Open Access This article is licensed under a Creative Commons Attribution 4.0 International License, which permits use, sharing, adaptation, distribution and reproduction in any medium or format, as long as you give appropriate credit to the original author(s) and the source, provide a link to the Creative Commons licence, and indicate if changes were made. The images or other third party material in this article are included in the article's Creative Commons licence, unless indicated otherwise in a credit line to the material. If material is not included in the article's Creative Commons licence and your intended use is not permitted by statutory regulation or exceeds the permitted use, you will need to obtain permission directly from the copyright holder. To view a copy of this licence, visit http://creativecommons.org/licenses/by/4.0/ The Creative Commons Public Domain Dedication waiver (http://creativecommons.org/publicdomain/zero/1.0/) applies to the data made available in this article, unless otherwise stated in a credit line to the data. 


\section{Introduction}

Globally, healthcare systems are facing great challenges due to increasing ageing population, chronic diseases, and economic restraints. Hospitals are under an increasing pressure to provide high quality services in an era of limited financial resources and growing expectations from patients and society [1]. Even though health technologies (HTs) play a key role and guidance exist on how these should be introduced, used and dismissed from hospitals [2-8], there is a gap in literature concerning the "awareness" of hospitals in the utilization of HTs. The relevance of the context has been reported in a study conducted among 53 hospital managers from nine European countries [9]. Although there are several attempts to identify contextual factors through different methodological approaches, such as expert panels and interviews, literature reviews, or research, there is not a clear consensus on how to define or assess them [10, 11]. Contextual factors have been defined as "the set of characteristics and circumstances or unique factors that surround a particular implementation effort" [12]. However, it is not clear whether it is the contextual factors that are affected by HTs, or if they may also affect the HTs' use in the first place. Among the most relevant attempts to theorize the dynamics existing between these dimensions, there is Leavitt's diamond framework, which describes the relationship between organizational structure, tasks, people and technology as well as the implications for change [13]. Furthermore, the relevance of hospitals' structural dimensions has been previosuly described in studies investigating the contextual factors that influence the adoption of HTs $[14,15]$. Nevertheless, the available evidence is still far from sufficient to draw clear conclusions on the impact that contextual dimensions have on the effective utilization of HTs and their value to patients' care. Indeed, most of the studies have focused on the process of formal adoption of HTs rather than on their concrete utilization and effective integration [14-16]. This poses great challenges to research efforts since these processes are deeply different one from the other, and are affected by organizational, individual, environmental, and innovation-related determinants [17, 18]. These determinants should be considered in order to create a more cost effective, resource efficient, informed health care service. In fact, the factors underlying successful implementations are not only those leading to the acquisition and introduction of a new technology, but also those capable of creating conditions that favor the effective and safe use of the new technology. The latter aspect is much less investigated. In addition, previous studies focusing on organizational or managerial factors affecting HTs' implementation, have not considered their collocation within a specific organizational setting, generating confusion between characteristics that may be ascribable to hospitals rather than to primary care settings $[16,19]$. Moreover, previous systematic reviews addressed these issues focusing on a specific HT, instead of considering all HTs' common factors [19]. These contextual factors, considered as essential to successful implementation of healthcare innovations [20], are barely recorded, analysed or considered when implementing change [21]. There is a clear need to investigate the impact of contextual factors on the actual use of HTs and on the value they bring to hospitals and patients. Such evidence is essential considering the changes in hospitals' organizational models and managerial policies and could lead to re-interpretations of Health Technology Assessment (HTA) reports, in light of a hospital's organizational scenario, overcoming the risk of rather uncritical applications, regardless of the specific context. Therefore, we conducted a systematic review to identify and summarize the contextual factors, in terms of hospital-specific organizational and managerial factors, that can affect the concrete implementation of HTs.

\section{Methods}

The systematic review is reported according to the Preferred Reporting Items for Systematic Reviews and MetaAnalyses (PRISMA) guidelines [22] (Additional file 1). The protocol of this systematic review has been included in the internal report of the Improved methods and actionable tools for enhancing HTA (IMPACT_HTA) Project (data not publicly available).

\section{Search strategy}

Data sources used were PubMed, Scopus, Web of Science, Ovid Medline and EconLit. Each electronic database was searched to identify relevant articles published in English and Italian language form January 1st, 2000 to January 1st, 2019. We have chosen this time range considering the fact that HTs have evolved a lot and quickly, therefore we think that it would not be appropriate or useful to compare the technological set-up of 30 years ago with that of today. We developed a search string consisting of the search terms and keywords. The keywords "hospital", "secondary care", "tertiary care", "biomedical technology", "technology", "facilitator", "barrier", "management", "organizational", "adoption, "acceptance", "implementation", “assimilation”, "uptake”, "utilization”, were combined using Boolean Operators and Medical Heading Subjects terms. The search strategy used in all the databases is reported in Additional file 2.

\section{Eligibility criteria}

The search question and the eligibility criteria for inclusion in the systematic review were developed according to the PICOS framework. 
P (population) - secondary or tertiary hospitals located within the European Union (EU) or within the Organisation for Economic Co-operation and Development (OECD);

I (intervention) - HT, using the definition of the World Health Organization (WHO) for HTs, as "the application of organized knowledge and skills in the form of devices, medicines, vaccines, procedures and systems developed to solve a health problem and improve quality of lives" $[23,18]$;; $\mathrm{C}$ (comparator) - There is not a comparator applicable for the studies in this systematic review;

O (outcome) - Contextual factors that facilitate or inhibit the implementation of a HT in a hospital setting;

We referred to those factors related to organization, infrastructure, support and capacity, team structure and collaboration, motivation to change, leadership and resources, that could potentially mediate the effect of a HT implementation and use.

S (study type) - Quantitative and qualitative studies reporting primary data were included.

Considering the PICOS developed for this systematic review, studies assessing contextual factors, facilitators and barriers related to the implementation of a HT in a secondary or tertiary hospital were considered eligible. Due to a lack of a standardised definition of implementation, we searched for all the concepts related to it, such as "adoption", "implementation", "acceptation" and "assimilation". Therefore, we included the articles that evaluated the actual utilization of a given $\mathrm{HT}$, referring to it as "HT implementation".

Studies that evaluated the technology implementation in primary care settings or the mere introduction of a HT in a hospital were excluded. Reviews (narrative, scoping or systematic), editorials, commentaries, conference abstracts and theoretical studies were excluded.

\section{Study selection}

The identified articles from all the databases were uploaded to Mendeley Software and the duplicates were removed. Two researchers (AG; IH) independently performed the initial step of screening based on title and abstracts. In a second step, two independent researchers (AG; IH) read carefully the articles with full texts available in order to decide the final articles to be included in the systematic review. Articles satisfying the eligibility criteria were selected for inclusion in the systematic review. Reasons for exclusion of full texts were recorded and were reported in the PRISMA flow chart. The reference lists of the included articles were carefully handsearched to retrieve additional eligible articles. Any discrepancies in the screening process and study selection were resolved by consulting a third reviewer (IG).

\section{Data extraction and synthesis}

Two researchers (AG; IH) independently extracted from each article the following data:

1) Study identification (first author, year of publication);

2) Study characteristics (country, study design, population, study size, response rate (in case of survey);

3) Information related to the HTs investigated (HT type, and the contextual factors affecting their implementation).

Any discrepancies in the data extraction process were resolved through discussion with a third author (IG).

Afterwards, we labelled the extracted contextual factors according to their topic and added up the studies that displayed each one. Additionally, these factors were grouped into the four areas: hospital's financial resources, leadership styles, human resource management and hospital infrastructure. Within each area, the contextual factors were described as either impeding or facilitating the implementation of the HT, as reported by each study. Each factor was checked in duplicate by two researchers (IH, AG.) and incongruence were resolved through discussion. If a study performed statistical analysis in order to investigate the relation between a given factor and the HT implementation, variables were categorised as facilitator in case of positive association and as barrier in case of negative association.

We performed a synthetic descriptive analysis of the studies according to the area of contextual factors.

\section{Quality assessment}

To assess the quality of the included studies we used the Critical Appraisal Skills Programme (CASP) checklist for qualitative studies [24]. As for the cross-sectional studies, the adapted version of Newcastle-Ottawa Scale (NOS) for cross-sectional studies was used [25]. The Mixed Methods Appraisal Tool [26] was used to assess the quality of mixed method studies. Two independent researchers $(\mathrm{AG}, \mathrm{IH})$ evaluated each article, and any disagreements were resolved through discussion.

\section{Results}

\section{Bibliographical search}

The search strategy identified 5472 articles from the five databases, as showed in detail in Fig. 1. After removing the duplicates, 3039 articles were retained for titles and abstract screening. A total of 216 full texts articled were read. After the screening process, 33 studies, [27-59] reporting original primary data, met the eligibility criteria for this systematic review. 


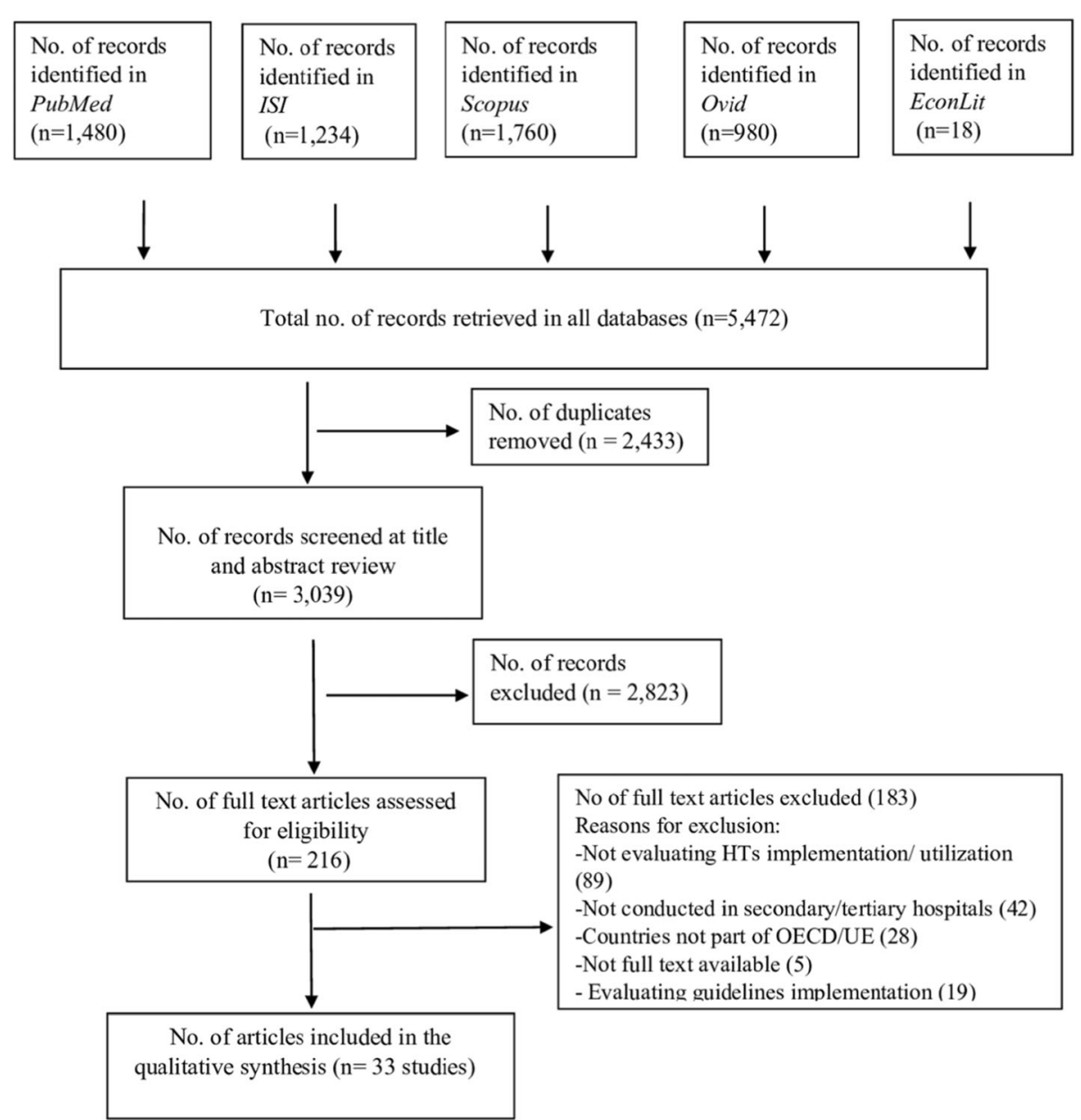

Fig. 1 Flow chart of literature search strategy

\section{Description of the studies}

The main characteristics of the included studies are reported in Table 1 . Twenty-seven (81.8\%) articles [27-36, 38-40, 45-48, 50-59] reported multicenter studies, involving up to 4606 hospitals. Seventeen studies (54.6\%) [27, 31, 32, 39, 41, 42, 44-46, 49, 50, 52, 53, 56-59] used qualitative approaches such as focus group discussions or descriptive methods, 13 studies (39.3\%) [28, 33-36, 38, 40, $43,47,48,51,54,55]$ applied a quantitative study design through surveys, while three studies $(9 \%)$ [29, 30, 37] implemented mixed methods. The response rate, when reported, varied from $12.5 \%$ [33] to 78\% [37]. The recruited participants were mainly hospital key stakeholders, hospitals' executives, physicians, nurses and clinical information officers (CIOs). Of the 33 studies, 12 (36\%) were conducted in USA [29, 30, 34, 37, 38, 44, 47-49, 51, 53, 58], five $(15 \%)$ in Canada $[28,39,40,50,52]$ and three (9\%) [31, 35, 41] in Australia. Among European countries, the majority of studies were conducted in UK [42, 45, 46, 56, 57] and Germany [33, 55, 59], five (15\%) and three (9\%) studies, respectively, followed by other countries with only one study. As for HTs investigated, 28 studies (82\%) evaluated information technologies (ITs), such as: electronic health record (EHR) [31, 36-38, 40, 42, 47, 48, 54, 56, 57], computerized physician order entry (CPOE) [53], health information technology (HIT) [28, 33, 44, 51, 58], standardized inpatient discharge model (SDM) [50], picture archiving and communication system (PACS) [39, 43], computerized decision support systems (CDSS) [27, 46]. Three studies (9\%) analyzed the following surgical interventions: thrombolysis procedure [52], transcatheter aortic valve implementation (TAVI) [59] and minimally invasive cardiac surgery (MICS) [30], and two studies (6\%) evaluated organizational technologies such as a surgical perioperative checklist for risk management [52] and palliative care in dementia and cancer settings [55].

\section{Quality assessment}

Seventeen studies (51.5\%) [27, 31, 32, 39, 41, 42, 44-46, 49, 50, 52, 53, 56-59], employing qualitative methods, were assessed using CASP (Additional file 3). The qualitative methods used were identified in all the studies, 


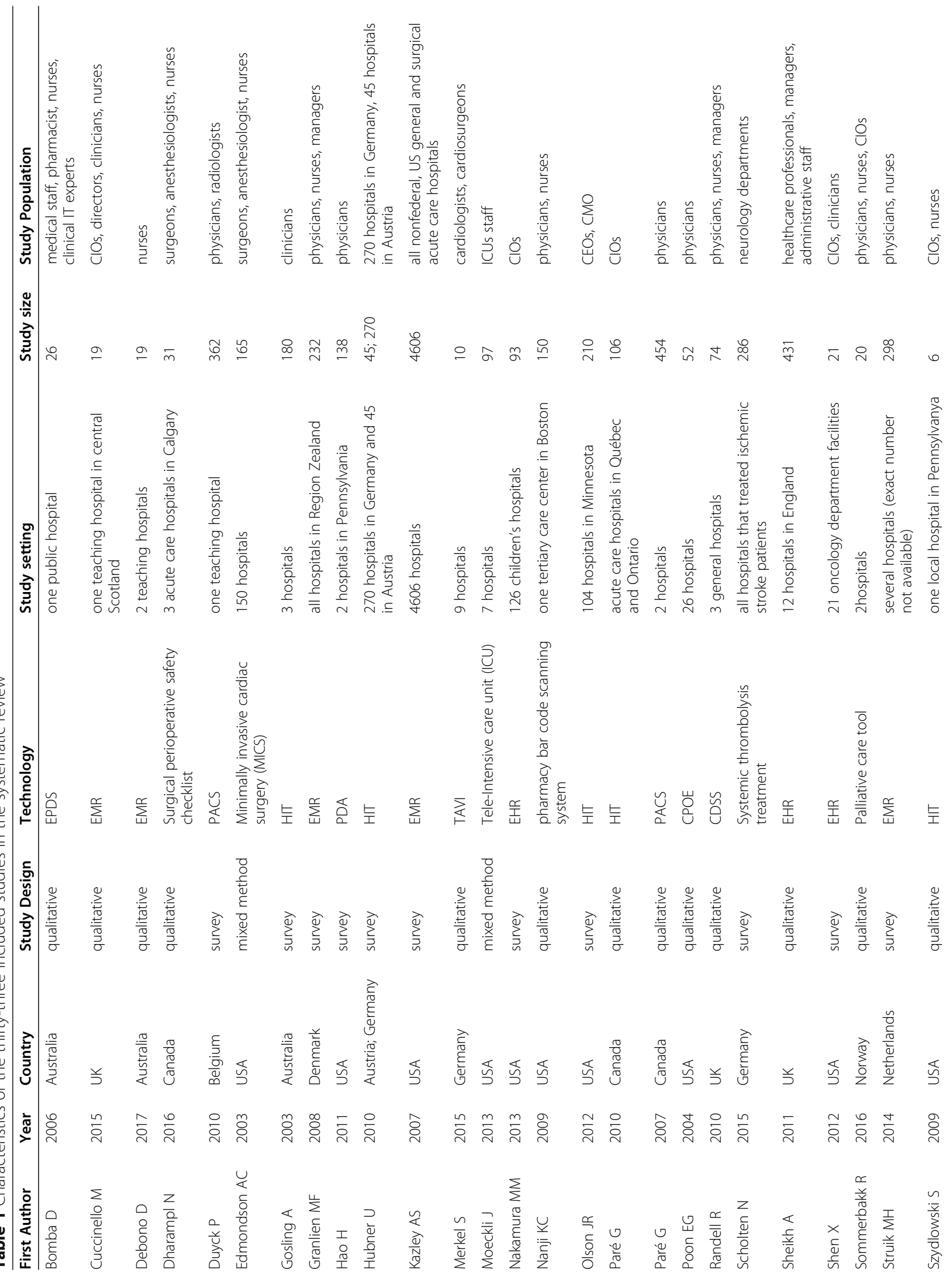




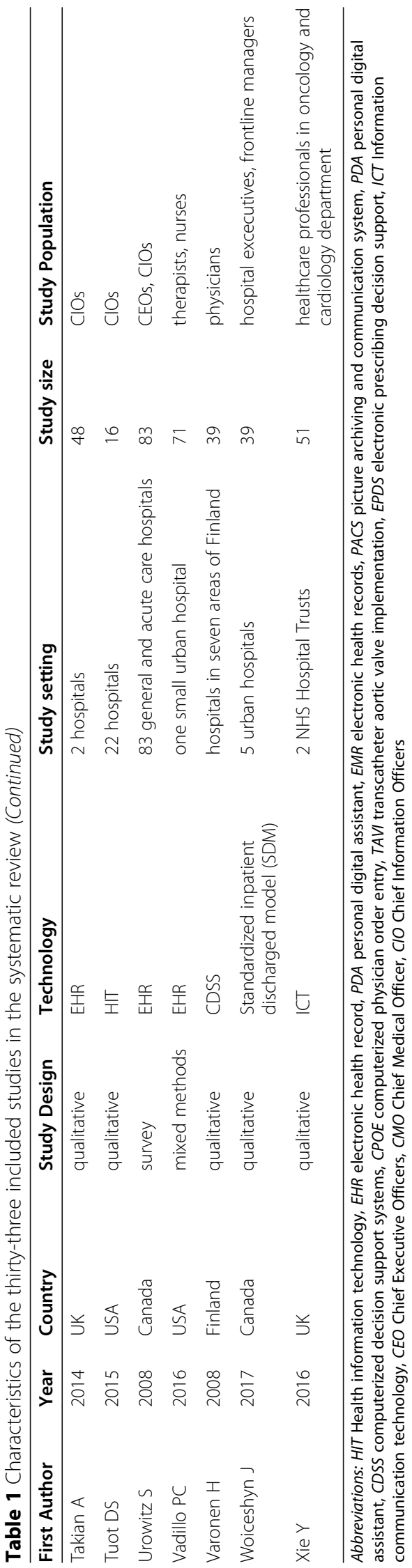


namely focus groups or semi-structured interviews. There was a clear statement of the objectives and a rational explanation why the qualitative study design was the most appropriate method for the research aim. Among all the studies, the researchers had explained in detail the selection criteria [56]. Ethical dimensions were reported in 12 studies $(70.5 \%)$ [27, 31, 32, 41, 42, 49, 50, 52, 56-59], in which institutional ethics committee approval and informed consent from participants were obtained. Data collection strategy was pertinent for specific qualitative method, and data analysis, sufficiently rigorous in all the studies, included a general coding of the interview transcripts based on the constructs of the conceptual framework used. In most of the studies, the qualitative analysis of the interview transcripts was conducted with an inductive approach, grouping the coded transcript text and then tabulating the items whereas, in three of them (17.7\%) [32, 46,59 ] a software was used. In all the studies, the authors pointed out the study limitations and the contribution of the results to the existing knowledge. The discussion of the findings was supported by evidence and directions for future research were suggested.

Thirteen studies (39\%) [28, 33-36, 38, 40, 43, 47, 48, $51,54,55]$, using quantitative methods, were appraised by NOS for cross-sectional studies (Additional file 4). In all the studies, the authors had described the sampling strategy, which mostly was representative of the target population. Not all the studies had compared the characteristics of the respondents and non-respondents while over half of them had reported the response rate. In two studies $(15 \%)[38,40]$, with an unsatisfactory response rate, the authors called for caution in interpreting the findings. The questionnaire used was not previously validated in five studies (38\%) [34, 36, 43, 54, 55], in which this was explicated in detail in the respective methods section. In all the studies, the most important confounding factors were controlled, and the statistical tests used for data analysis were clearly explained. Eleven studies (85\%) [28-30, 33-36, 38, 40, 43, 48, 51, 54] used questionnaires for the outcome ascertainment. After evaluating if the specific criteria were met in each study, the score ranged from five to eight, appraising studies of moderate to high quality.

The Mixed Methods Appraisal Tool was used to assess the quality of three studies $[29,30,37]$ that had clearly demonstrated why the mixed method was chosen to address the research question (Additional file 5). The criteria of each method were satisfied by all the studies. Only in two studies $[29,30]$ the qualitative and quantitative components were effectively integrated to answer the research question and the outputs were adequately interpreted. Vadillo et colleagues [37] reported different outcomes interpretations for the two components, focus group and semi-structured interviews.

\section{Evidence from the studies}

The contextual factors relevant for the implementation of HTs are reported in Table 2 and in details in Additional file 6. These factors can be ascribable to four main areas: hospital's financial resources, leadership styles, human resource management and hospital infrastructure.

The first area concerned hospital's financial resources. According to the results of 13 studies (39\%) [27-29, 32, $40,41,44-46,50,53,59,60]$, financial support and adequate budgeting are of utmost importance for successful HTs implementation. Resources have been identified as a barrier when hospitals faced difficulties obtaining funding for high-cost technology or for recruiting technical staff. Poon et al. [53] stated that the high cost of CPOE implementation forced hospital officials to consider other priorities. The absence of a budget that is coherent with organizational units' technological assets may hinder the possibility of their concrete use. Merkel et al. [59], while investigating the use of TAVI among cardiologists and cardio-surgeons, reported cost issues and lack of reimbursement policies as the main cause of a sub-optimal use of the HT.

Second, a total of 12 articles (36\%) [28, 30, 32, 34, 42, $44,50,53,57-59]$ mentioned leadership as a required factor to successfully implement HTs. In most of these studies, researchers found that a persistent and sustained leadership by top management was a key element to successfully implement the HT. Takian et al. [57] stated that an insightful leadership, as well as the managerial team which was signed-up to the vision of EHR, were crucial for its implementation, acting as a boundary spanner that bridged the gap between implementation team and end users. Moreover, Poon et al. [53] considered leadership as one of the major strategies to overcome resistance to change that inevitably occurred in CPOE implementation among physicians. In a study conducted in Norway [32], researchers demonstrated that distant management led to a lack of detailed understanding of the tasks involved in patient care by operators. Further, the fact of nurses not being represented in the management group, and therefore not involved in the decision-making processes regarding organizational change, was a possible barrier to the implementation of HTs. Factors such as managers' attitude and propensity to involve staff members in decision-making processes were considered a facilitator factor by six studies $(18.1 \%)$ [29, 32, 39, 42, 49, 54]. In addition, opinion leaders seemed to influence peers' attitudes towards a new technology [34, 39, 49, 58]. The opinion leader's effect is strictly connected, although not coincident, to top management's support and leadership style. Frontline managers of urban hospitals in Canada, as the executive champions, tend to integrate innovation initiatives with 
Table 2 Summary of determinants influencing the actual utilization of HTs

\begin{tabular}{|c|c|c|}
\hline Areas of determinants & Influence of determinants on actual utilization of HTs & References \\
\hline \multirow{6}{*}{$\begin{array}{l}\text { Financial support and } \\
\text { adequate budgeting }\end{array}$} & Hospital financial resources hinders actual utilization & {$[22-27,35,36,39-41,45,48,54,55]$} \\
\hline & $\begin{array}{l}\text { High cost technologies force the hospital to consider } \\
\text { other priorities }\end{array}$ & [48] \\
\hline & $\begin{array}{l}\text { Financial difficulties impact on recruiting and retaining } \\
\text { technical staff }\end{array}$ & {$[41,48]$} \\
\hline & Reimbursement policies might facilitate HT utilization & {$[53,54]$} \\
\hline & Financial self-sufficiency represents a necessary condition & [34] \\
\hline & $\begin{array}{l}\text { Funding model for specialist clinician reimbursement } \\
\text { facilitates HT utilization }\end{array}$ & [53] \\
\hline \multirow[t]{9}{*}{ Leadership } & Leadership enables to: & \\
\hline & $\begin{array}{l}\text {-shorten the gap between implementation team and } \\
\text { end users }\end{array}$ & [52] \\
\hline & -overcome resistance to change & [48] \\
\hline & -ameliorate understanding of $\mathrm{HT}$ and tasks & [27] \\
\hline & -involve end users in the decision-making process & {$[24,27,34,37,44,49]$} \\
\hline & -positively influence attitude toward new HTs & {$[29,34,44,53]$} \\
\hline & $\begin{array}{l}\text {-adapt the HT integration to the needs of the work } \\
\text { environment }\end{array}$ & {$[34,41]$} \\
\hline & Champions and top opinion leaders drive the integration & [45] \\
\hline & Champions facilitate communication and team work & {$[54,25]$} \\
\hline \multirow{6}{*}{$\begin{array}{l}\text { Human Resources } \\
\text { Management }\end{array}$} & Human Resources Management enables to: & \\
\hline & $\begin{array}{l}\text { - define and resource new roles capable of supporting } \\
\text { and sustaining the change }\end{array}$ & {$[34,37,41,44,54]$} \\
\hline & $\begin{array}{l}\text { - appropriately manage staff recruitment preventing } \\
\text { staff shortages and contractual tensions }\end{array}$ & {$[26,27,31,33,34,38,39,48,51]$} \\
\hline & - ensure appropriate training to end users & {$[24,32,33,37,38,38,41,44,49,51,52]$} \\
\hline & - take into account concerns about time-consuming training & {$[39,49,36]$} \\
\hline & $\begin{array}{l}\text { - address concerns about new HT (e.g. changes to workload, workflow) } \\
\text { - improve cooperation and team working }\end{array}$ & {$[22,26,31,36,44,47,51,34,44,48,53,54]$} \\
\hline \multirow[t]{3}{*}{ Structure } & $\begin{array}{l}\text { Technological capability is a latent process that enables HT } \\
\text { utilization }\end{array}$ & {$[23,28,33,34,36,42,43,46,50-52,54]$} \\
\hline & Large size and urban location might positively influence utilization & {$[42,23]$} \\
\hline & Teaching hospitals might be positively associated with utilization & [43] \\
\hline
\end{tabular}

ongoing projects, so that staff incorporation would be as supportive as possible [50]. In the same line, in Merkel et al. [59] and in Edmondson et al. [30], the presence of a champion was essential in facilitating the dialogue between the cardiologists and cardiosurgeons, in order to drive the implementation forward. Managing integration into current practice was also held to be fundamental. Often HTs led to the reorganization of departments and workflows [49, 52, 53, 58]. As a consequence, some authors stated that the implementation strategy should take several aspects into account and adapt specifically to the working environment needs rather than simply being a "technical" project $[39,46]$.

Third, Human Resource Management (HRM) was another important factor emerging in several studies. HRM appears to cover a crucial role in the phase of staff supply and planning, due to the need to define new roles, including those in charge to support the change $[39,42,46,49,59]$. Insufficient or inadequate human resources, staff shortages, lack of staff recruitment and contractual tensions were considered barriers for HTs implementation in nine (26\%) studies [31, 32, 36, 38, 39, $43,44,53,56]$. Moreover, HRM is also essential to plan education and to inform providers. To effectively use a given technology it is often necessary to undergo an appropriate training program and many studies underlined that the inability to satisfy true training needs was considered a major barrier for implementation [29, 37, 38, $42-44,46,49,54,56,57]$. Although it was stated that education might be a time-consuming activity [44, 54] and should be cautiously planned [41], in general training programs are considered among the most 
determinant factors for an effective implementation. Experts and clinicians in Bomba et al. [41], concerned about the feasibility of training initiatives in a 24-h, 7days per week operating environment, proposed the application of innovative methods of training such as video and online courses. Nevertheless, not only training in a strict sense but also "general communication" may play a major role. Indeed, some authors noticed that the utilization of a HT could cause a perceived waste of time or an extra workload, inducing utilizers to "reject" the HT or to use it against their will, in sub-optimal ways $[27,31,36,41,49,52,56]$. In this context, it is important that HRM tools are coherent with the hospital organizational and technological asset [24] and spur operators to "accept" the HT, addressing their concerns, including those related to workflow changes $[39,49,53$, $58,59]$. That was the case of the staff acceptance of a telemedicine ICU where participants complained the HT was disrupting staff communication making the job harder [24]. A final dimension in which HRM was held to make a solid difference is the generation and allocation of specific behavioral competencies. In particular, team-working emerged as a fundamental factor for HTs' implementation in 14 studies (42\%) [29-32, 35, 39, 44, $49,50,52,53,57,59]$. For instance, the study by Edmonson et al. [30], conducted with 16 multi-disciplinary teams of medical staff in 16 hospitals, suggested that team communication led to the successful implementation of surgical procedures. Further, according to their results, teams with better internal communication are likely to expand also external communication with other teams, empowering the implementation process. In other studies, researchers found that a lack of mutual communication and team cooperation is a limiting factor for HTs' implementation [31, 52, 59].

Finally, evidence also suggests that some determinants related to the infrastructure of the hospitals might influence HTs' implementation. For instance, the technological capability of the hospital (the characteristics of the set of all other technologies available) or even the affiliation to some universities or to a multihospital network, could be associated to HTs' implementation [28, $33,38,39,41,47,48,51,55-57,59]$.

\section{Discussion}

The present work provides a novel point of view in understanding how hospital contextual factors may hinder or facilitate a full implementation of HTs. Although HTA is attentive to capture the effects of technologies on multiple domains (among which the organizational one), the inverse relationship, i.e. how organizational/ contextual factors may affect HTs' implementation, remains unexplored. Addressing this query implies ascribing to HTs the power of "producing value" within patients' continuum of care. The term "value", here, is ascribable to Porter's definition, which is defined as "the patient health outcomes achieved per dollar spent". As stated by Porter, "value encompasses many of the other goals already embraced in healthcare, such as quality, safety, patient-centeredness, and cost containment, and integrates them. It is also fundamental to achieving other important goals such as improving equity and expanding access at reasonable cost" [61].

This systematic review provides valuable insights concerning the relationship between contextual factors and HTs' implementation. Our results, in line with previous evidence, showed that facilitators and barriers to HTs' implementation vary across studies and countries. However, this work suggests that facilitators and barriers to the actual utilization of HTs could be reconducted to four overarching domains. The first dimension concerns the hospital's availability of financial resources. Although intuitive in principle, this finding has further implications than the mere ascertainment that a hospital with more resources is advantaged in implementing the use of HTs. Indeed, implications concern the internal distribution of resources and their coherence with organizational units' technological assets. This, in turn, provides food for thought on the consequences of misaligning HTs and budgets within or across organizational units.

The second dimension that affects HTs' implementation refers to leadership styles and management. What seems to emerge here is that HTs should be driven in a very participative manner. Top management involvement is required to implement HTs, suggesting that an excessive decentralization of responsibilities to lower levels may hinder implementation. On the other hand, it emerges clearly that top management has a role of "mediation" of professionals, to be exerted by involving professionals at all levels - including nurses and final utilizers of the HT. This provides interesting implications in terms of managerial styles, suggesting an increased effectiveness of attitudes that approach a concern for people rather than a concern for results [62].

Third, HRM appears fundamental in utilizing HTs. HRM seems to have a major impact in terms of planning people's work, both through "standard" training pathways and the development of behavioral skills such as, team-working. Development and integration of technical and behavioral skills is challenging, especially in a dynamic and complex sector such as healthcare, where the need for education is of utmost importance. In particular, future research should address the relevant topic of how incentive schemes may affect the use of HTs. This may be of great interest in an era in which hospitals are increasingly required to be accountable and tend to introduce Management by Objectives logics within their daily functioning [63]. Finally, no evidence was identified 
in terms of managerial accounting tools. It is expected that a structured, integrated, and well-functioning set of tools, able to collect and analyze data, would affect the use of HTs. This is strictly related to hospitals' ability and swiftness in enhancing communication within and across hospital units, as well as at the interorganizational level.

The role of of the identified contextual factors could depend on the environmental context in which the hospital operates. A systematic review that evaluated the influence of context on quality improvement reported that variations in the characteristics of the external context in different sites, such as physical environment, sociocultural context or political and funding environment can influence implementation outcome [64]. Future research should examine whether some specific contextual factors are more important in specific settings, to provide the information needed to translate the technology implementation to different settings and situations.

Although this systematic review employed a robust methodological approach and it was rigorously conducted, few limits need to be identified. In the first place, as in all systematic reviews, our study might be subject to publication bias. Even though the search strategy was performed in five databases, we only included articles published in English and Italian language, from January 1st, 2000 until January 1st, 2019, suggesting that we may have missed a number of articles. We acknowledge that the search strategy is rather extensive in scope and may lack analytical evidence on specific aspects of HTs' implementation. Even though the search may not have identified all relevant literature, this risk of publication bias has been minimised by manually screening the reference lists of the included articles. However, although it is of utmost importance to analytically target specific features of implementation, with attention to specific types of HTs, the intent of the authors was to generate a broad evidence of the state of the art in literature, in order to assess the desirable directions of future research. We also acknowledge that, even if we restricted our search to OECD, differences across countries (e.g. private or public healthcare systems) might be relevant and generalization of our findings should be cautious. Even though our systematic review was not restricted to any type of HTs, the vast majority of studies concerned information and communication technologies, and nothing emerged in reference to clinical equipment and drugs.

Understanding the relationship occurring between hospital contextual factors and the implementation of HTs is an arduous task. On one hand it is clear that HTs may affect the context, on the other the inverse relationship also seems to hold true. Although HTA has definitively incorporated the organizational domain within its span of interest, the way in which this domain may enable or hinder a full implementation of HTs is still rather unclear. This work has the potential to contribute to a better understanding in this direction. Policy makers often face challenges when making decisions regarding the evaluation and implementation of HTs. Therefore, we believe that our results might contribute to the development of strategies addressing these factors, aiming a successful implementation.

\section{Conclusions}

To conclude, there seem to exist two main gaps in literature: one concerning the contextual factors of interest that could play a role when implementing a HT. Although relevant evidence has emerged, several items, such as managerial accounting tools may have been overlooked. The second, -and perhaps more salient one, concerning the typologies of HTs investigated. Elucidating contextual factors is essential to identify effective, sustainable, and reproducible strategies that aim to overcome the barriers and improve HTs' implementation. Future research is needed to shed light in this direction, providing guidance to hospital management, to reduce the uncertainty of the concrete effects produced by HT in settings that present numerous contingent factors.

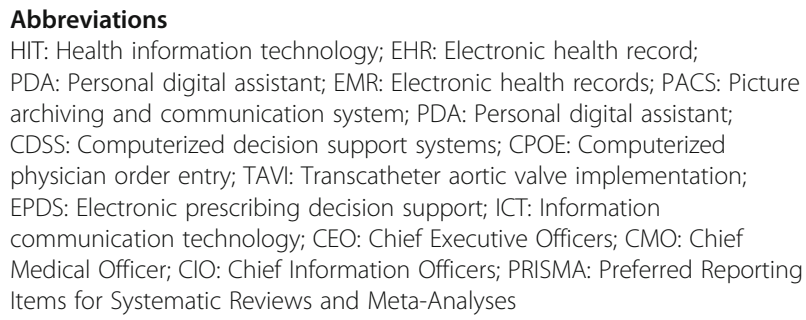

\section{Supplementary Information}

The online version contains supplementary material available at https://doi. org/10.1186/s12913-021-06423-2.

\section{Additional file 1. \\ Additional file 2. \\ Additional file 3. \\ Additional file 4. \\ Additional file 5 . \\ Additional file 6 .}

\section{Acknowledgments}

This study was undertaken as part of the IMPACT HTA project [Grant Agreement Number 779312], an initiative funded by the European Union within the Horizon 2020 research and innovation program.

\section{Authors' contributions}

$A C$ and SB conceptualized the research questions, contributed to the final version of the manuscript and supervised the research project. AG and $\mathrm{IH}$ permormed the research in the electronic databases and independently conducted the screening and study selection phase and the quality assessment of the included studies. Also AG and IH both wrote the introduction, methods results and discussion section of the manuscript. IG conceptualize the searching strategy and wrote the introduction, discussion 
and conclusion section. MLS supervised the search strategy and the results interpretation. CdW revised each step of the research and critically revised the manuscript preparation process. All authors read and approved the final manuscript.

\section{Funding}

This work was supported by the European Commission - Directorate-General Research \& Innovation [Grant number 779312] as part of the IMPACT HTA project.

\section{Availability of data and materials}

The datasets used and/or analysed during the current study are available from the corresponding author on reasonable request.

\section{Declarations}

Ethics approval and consent to participate

Not applicable.

\section{Consent for publication}

Not applicable.

\section{Competing interests}

The authors declare that they have no competing interests.

\section{Author details}

${ }^{1}$ Section of Hygiene, University Department of Life Sciences and Public Health, Università Cattolica del Sacro Cuore, Largo Francesco Vito, 1, 00168 Rome, Italy. ${ }^{2}$ Graduate School of Health Economics and Management (ALTE MS), Faculty of Economics, Università Cattolica del Sacro Cuore, Rome, Italy. ${ }^{3}$ Clinical Governance Unit, Fondazione Policlinico Universitario A. Gemelli IRCCS, Rome, Italy. ${ }^{4}$ Department of Woman and Child Health and Public Health - Public Health Area, Fondazione Policlinico Universitario A. Gemelli IRCCS, Rome, Italy. ${ }^{5}$ Department of Medicine and Surgery, University of Perugia, Perugia, Italy.

\section{Received: 20 November 2020 Accepted: 19 April 2021}

\section{Published online: 01 May 2021}

\section{References}

1. OECD. New health technologies: managing access, value and sustainability: OECD Publishing; 2017. https://doi.org/10.1787/9789264266438-en.

2. EUnetHTA. Guideline Therapeutic medical devices. 2015. https://eunethta. eu/wp-content/uploads/2018/01/Therapeutic-medical-devices_Guideline_ Final-Nov-2015.pdf. Accessed 15 July 2020

3. National Institute for Health and Care Excellence. Diagnostics assessment programme manual. London: National Institute for Health and Care Excellence (NICE); 2011.

4. Technical Guidelines for preparing assessment reports for the Medical Services Advisory Committee-Medical Service Type: Therapeutic (Version 2. 0). 2016. http://www.msac.gov.au/internet/msac/publishing.nsf/Content/ OBD63667C984FEEACA25801000123AD8/\$File/TherapeuticTechnica IGuidelines-Final-March2016-Version2.0-accessible.pdf. Accessed 15 July 2020.

5. Toronto: Health Quality Ontario Health Technology Assessment - Health Quality Ontario (HQO). https://www.hqontario.ca/Evidence-to-Improve-Care/ Health-Technology-Assessment. Accessed 15 July 2020.

6. Tarricone R, Torbica A, Drummond M. Key recommendations from the MedtecHTA project. Health Econ. 2017;26:145-52. https://doi.org/10.1002/ hec.3468.

7. Kolasa K, Schubert S, Manca A, Hermanowski T. A review of Health Technology Assessment (HTA) recommendations for drug therapies issued between 2007 and 2009 and their impact on policymaking processes in Poland. Health Policy. 2011;102(2-3):145-51. https://doi.org/10.1016/j.healthpol.2011.05.001.

8. Huic M, Tandara Hacek R, Svajger I. Health technology assessment in Central, Eastern, and South European countries: croatia. Int J Technol Assess Health Care. 2017;33(3):376-83. https://doi.org/10.1017/S026646231700054X.

9. Kidholm K, Ølholm AM, Birk-Olsen M, Cicchetti A, Fure B, Halmesmäki E, et al. Hospital managers' need for information in decision-making--an interview study in nine European countries. Health Policy. 2015;119(11): 1424-32. https://doi.org/10.1016/j.healthpol.2015.08.011.
10. Kringos DS, Sunol R, Wagner $C$, et al. The influence of context on the effectiveness of hospital quality improvement strategies: a review of systematic reviews quality, performance, safety and outcomes. BMC Health Serv Res. 2015;15(1):277. https://doi.org/10.1186/s12913-015-0906-0.

11. Ogrinc G, Davies L, Goodman D, Batalden P, Davidoff F, Stevens D. SQUIRE 2.0 (standards for QUality improvement reporting excellence): revised publication guidelines from a detailed consensus process. BMJ Qual Saf. 2016;25(12):986-92. https://doi.org/10.1136/bmjqs-2015-004411.

12. Damschroder LJ, Aron DC, Keith RE, Kirsh SR, Alexander JA, Lowery JC. Fostering implementation of health services research findings into practice: a consolidated framework for advancing implementation science. Implement Sci. 2009;4(1):50. https://doi.org/10.1186/1748-5908-4-50.

13. Leavitt H. Applied organisational change in industry: Structural, technological and humanistic approaches. In: J. G. March (Ed.), Handbook of organisation. Chicago: Rand McNally and Company; 1965.

14. Cresswell K, Sheikh A. Organizational issues in the implementation and adoption of health information technology innovations: an interpretative review. Int J Med Inform. 2013;82(5):e73-86. https://doi.org/10.1016/J. IJMEDINF.2012.10.007.

15. Garavand A, Mohseni M, Asadi H, Etemadi M, Moradi-Joo M, Moosavi A. Factors influencing the adoption of health information technologies: a systematic review. Electron Physician. 2016;8(8):2713-8. https://doi.org/10.19082/2713.

16. Gagnon MP, Desmartis M, Labrecque M, Car J, Pagliari C, Pluye P, et al. Systematic review of factors influencing the adoption of information and communication technologies by healthcare professionals. J Med Syst. 2012; 36(1):241-77. https://doi.org/10.1007/s10916-010-9473-4.

17. Varabyova Y, Blankart CR, Greer AL, Schreyögg J. The determinants of medical technology adoption in different decisional systems: a systematic literature review. Health Policy. 2017;121(3):230-42. https://doi.org/10.1016/j. healthpol.2017.01.005.

18. Esmaeilzadeh P, Sambasivan M, Kumar N, Nezakhati H. Adoption of Technology Applications in Healthcare: The Influence of Attitude toward Knowledge Sharing on Technology Acceptance in a Hospital. In: Kim T. et al. (eds) U- and E-Service, Science and Technology. UNESST 2011. Communications in Computer and Information Science, vol 264. Berlin: Springer; 2011. https://doi.org/10.1007/978-3-642-27210-3 3.

19. Ross J, Stevenson F, Lau R, Murray E. Factors that influence the implementation of e-health: a systematic review of systematic reviews (an update). Implement Sci. 2016;11(1):146. https://doi.org/10.1186/s13012-016-0510-7.

20. Bate P, Robert G, Fulop N, Ovretveit J, Dixon-Woods M. Perspectives on context. A selection of essays considering the role of context in successful quality improvement. London: Health Foundation; 2014.

21. Tomoaia-Cotisel A, Scammon DL, Waitzman NJ, Cronholm PF, Halladay JR, Driscoll DL, et al. Context matters: the experience of 14 research teams in systematically reporting contextual factors important for practice change. Ann Fam Med. 2013;11(Suppl 1):S115-23. https://doi.org/10.1370/afm.1549.

22. Kleijnen J, loannidis JPA, Moher D, et al. The PRISMA statement for reporting systematic reviews and meta-analyses of studies that evaluate health care interventions: explanation and elaboration. J Clin Epidemiol. 2009;62(10):e1-e34. https://doi.org/10.1016/j.jclinepi.2009.06.006.

23. WHO. WHO I what is a health technology? https://www.who.int/healthtechnology-assessment/about/healthtechnology/en/. Accessed July 2020.

24. CASP (2018) CASP. https://casp-uk.net/casp-tools-checklists. Accessed 15 July 2020.

25. Herzog R, Álvarez-Pasquin MJ, Díaz C. et al. Are healthcare workers' intentions to vaccinate related to their knowledge, beliefs and attitudes? a systematic review. BMC Public Health. 2013:13:154. https://doi.org/10.11 86/1471-2458-13-154.

26. Hong QN, Fàbregues S, Bartlett G, Boardman F, Cargo M, Dagenais P, et al. The Mixed Methods Appraisal Tool (MMAT) version 2018 for information professionals and researchers. Education for Information. 2018;34(4):285-91.

27. Varonen H, Kortteisto T, Kaila M, EBMeDS Study Group. What may help or hinder the implementation of computerized decision support systems (CDSSs): a focus group study with physicians. Fam Pract. 2008;25(3):162-7. https://doi.org/10.1093/fampra/cmn020.

28. Paré $G$, Jaana $M$, Sicotte $C$. Exploring health information technology innovativeness and its antecedents in Canadian hospitals. Methods Inf Med. 2010:49(01):28-36. https://doi.org/10.3414/ME09-01-0027.

29. Moeckli J, Cram P, Cunningham C, Reisinger HS. Staff acceptance of a telemedicine intensive care unit program: a qualitative study. J Crit Care. 2013;28(6):890-901. https://doi.org/10.1016/j.jcrc.2013.05.008. 
30. Edmondson AC. Speaking up in the operating room: how team leaders promote learning in interdisciplinary action teams. J Manag Stud. 2003;40(6): 1419-52. https://doi.org/10.1111/1467-6486.00386.

31. Debono D, Taylor N, Lipworth W, Greenfield D, Travaglia J, Black D, et al. Applying the theoretical domains framework to identify barriers and targeted interventions to enhance nurses' use of electronic medication management systems in two Australian hospitals. Implement Sci. 2017;12(1): 42. https://doi.org/10.1186/s13012-017-0572-1.

32. Sommerbakk R, Haugen DF, Tjora A, Kaasa S, Hjermstad MJ. Barriers to and facilitators for implementing quality improvements in palliative care results from a qualitative interview study in Norway. BMC Palliat Care. 2016; 15(1):61. https://doi.org/10.1186/s12904-016-0132-5.

33. Hübner U, Ammenwerth E, Flemming D, Schaubmayr C, Sellemann B. IT adoption of clinical information systems in Austrian and German hospitals: results of a comparative survey with a focus on nursing. BMC Med Inform Decis Mak. 2010;10(1):8. https://doi.org/10.1186/1472-6947-10-8.

34. Hao H, Padman R, Telang R. An empirical study of opinion leader effects on mobile information technology adoption in healthcare. AMIA Annu Symp Proc. 2011;2011:537-42.

35. Gosling AS, Westbrook J, Braithwaite J. Clinical team functioning and IT innovation: a study of the diffusion of a point-of-care online evidence system. J Am Med Inform Assoc. 2003;10(3):244-51. https://doi.org/10.1197/ jamia.M1285.

36. Granlien MF, Hertzum M, Gudmundsen J. The gap between actual and mandated use of an electronic medication record three years after deployment. Stud Health Technol Inform. 2008;136:419-24.

37. Vadillo PC, Rojo ES, Garces A, Checton MG. Maximizing Healthcare Professionals' Use of New Computer Technologies in a Small, Urban Hospital's Critical Care Unit. J Healthc Manag. 2016;61(5):352-62.

38. Shen X, Dicker AP, Doyle L, Showalter TN, Harrison AS, DesHarnais SI. Pilot study of meaningful use of electronic health Records in Radiation Oncology. J Oncol Pract. 2012;8(4):219-23. https://doi.org/10.1200/JOP.2011.000382.

39. Paré G, Trudel M-C. Knowledge barriers to PACS adoption and implementation in hospitals. Int J Med Inform. 2007;76(1):22-33. https://doi. org/10.1016/j.jmedinf.2006.01.004.

40. Urowitz S, Wiljer D, Apatu E, Eysenbach G, DeLenardo C, Harth T, et al. Is Canada ready for patient accessible electronic health records? A national scan. BMC Med Inform Decis Mak. 2008;8(1):33. https://doi.org/10.1186/14 72-6947-8-33.

41. Bomba D, Land T. The feasibility of implementing an electronic prescribing decision support system: a case study of an Australian public hospital. Aust Health Rev. 2006;30(3):380-8. https://doi.org/10.1071/AH060380.

42. Cucciniello M, Lapsley I, Nasi G, Pagliari C. Understanding key factors affecting electronic medical record implementation: a sociotechnical approach. BMC Health Serv Res. 2015;15(1):268. https://doi.org/10.1186/s12 913-015-0928-7

43. Duyck P, Pynoo B, Devolder P, Voet T, Adang L, Ovaere D, et al. Monitoring the PACS implementation process in a large university hospital-discrepancies between radiologists and physicians. J Digit Imaging. 2010; 23(1):73-80. https://doi.org/10.1007/s10278-008-9163-7.

44. Szydlowski S, Smith C. Perspectives from nurse leaders and chief information officers on health information technology implementation. Hosp Top. 2009;87(1):3-9. https://doi.org/10.3200/HTPS.87.1.3-9.

45. Xie Y, Breen L, Cherrett T, Zheng D, Allen CJ. An exploratory study of reverse exchange systems used for medical devices in the UK National Health Service (NHS). Supply Chain Manag. 2016;21(2):194-215. https://doi. org/10.1108/SCM-07-2015-0278.

46. Randell R, Dowding D. Organisational influences on nurses' use of clinical decision support systems. Int J Med Inform. 2010;79(6):412-21. https://doi. org/10.1016/j.jmedinf.2010.02.003.

47. Kazley AS, Ozcan YA. Organizational and environmental determinants of hospital EMR adoption: a National Study. J Med Syst. 2007;31(5):375-84. https://doi.org/10.1007/s10916-007-9079-7.

48. Nakamura MM, Harper MB, Jha AK. Change in adoption of electronic health records by US Children's hospitals. Pediatrics. 2013;131(5):e1563-75. https:// doi.org/10.1542/peds.2012-2904.

49. Nanji KC, Cina J, Patel N, Churchill W, Gandhi TK, Poon EG. Overcoming barriers to the implementation of a pharmacy Bar code scanning system for medication dispensing: a case study. J Am Med Inform Assoc. 2009;16(5): 645-50. https://doi.org/10.1197/jamia.M3107.
50. Woiceshyn J, Blades K, Pendharkar SR. Integrated versus fragmented implementation of complex innovations in acute health care. Health Care Manag Rev. 2017;42(1):76-86. https://doi.org/10.1097/HMR. 0000000000000092 .

51. Olson NA, Davidow AL, Winston CA, Chen MP, Gazmararian JA, Katz DJ. A national study of socioeconomic status and tuberculosis rates by country of birth, United States, 1996-2005. BMC Public Health. 2012;12(1). https://doi. org/10.1186/1471-2458-12-365.

52. Dharampal N, Cameron C, Dixon E, Ghali W, Quan ML. Attitudes and beliefs about the surgical safety checklist: just another tick box? Can J Surg. 2016; 59(4):268-75. https://doi.org/10.1503/CJS.002016.

53. Poon EG, Blumenthal D, Jaggi T, Honour MM, Bates DW, Kaushal R. Overcoming barriers to adopting and implementing computerized physician order entry systems in U.S. hospitals. Health Aff. 2004;23(4):184-90. https://doi.org/10.1377/hlthaff.23.4.184.

54. Struik MH, Koster F, Schuit AJ, et al. The preferences of users of electronic medical records in hospitals: quantifying the relative importance of barriers and facilitators of an innovation. Implement Sci. 2014;9(1):69. https://doi. org/10.1186/1748-5908-9-69.

55. Scholten N, Pfaff H, Lehmann HC, Fink GR, Karbach U. Who does it first? The uptake of medical innovations in the performance of thrombolysis on ischemic stroke patients in Germany: a study based on hospital quality data. Implement Sci. 2015;10(1):10. https://doi.org/10.1186/s13012-014-0196-7.

56. Sheikh A, Cornford T, Barber N, Avery A, Takian A, Lichtner V, et al. Implementation and adoption of nationwide electronic health records in secondary care in England: final qualitative results from prospective national evaluation in \&quot;early adopter\&quot; hospitals. BMJ. 2011;343(oct17 1): d6054. https://doi.org/10.1136/bmj.d6054.

57. Takian A, Sheikh A, Barber N. Organizational learning in the implementation and adoption of national electronic health records: case studies of two hospitals participating in the National Programme for information Technology in England. Health Informatics J. 2014;20(3):199-212. https://doi. org/10.1177/1460458213493196.

58. Tuot DS, Leeds K, Murphy EJ, Sarkar U, Lyles CR, Mekonnen T, et al. Facilitators and barriers to implementing electronic referral and/or consultation systems: a qualitative study of 16 health organizations. BMC Health Serv Res. 2015;15(1):568. https://doi.org/10.1186/s12913-015-1233-1.

59. Merkel S, Eikermann M, Neugebauer EA, von Bandemer S. The transcatheter aortic valve implementation (TAVI) - a qualitative approach to the implementation and diffusion of a minimally invasive surgical procedure. Implement Sci. 2015;10(1):140. https://doi.org/10.1186/s13012-015-0330-1.

60. Solà Bonada N, María Álvarez Díaz A, Jané CC. The role of the Pharmacist in the design, development and implementation of Medication Prescription Support Systems Papel del farmacéutico en el diseño, desarrollo e implantación de sistemas de soporte a la prescripción de medicamentos. Farm Hosp. 2016;40(n06):457-76. https://doi.org/10.7399/fh.2016.40.6.10440.

61. Gabutti I, Mascia D, Cicchetti A. Exploring "patient-centered" hospitals: a systematic review to understand change. BMC Health Serv Res. 2017;17(1): 364. https://doi.org/10.1186/s12913-017-2306-0.

62. Blake RR, Mouton JS. Management by Grid ${ }^{\circledR}$ principles or situationalism: Which? Group \& Organization Studies. 1981;6(4):439455. https://doi.org/1 $0.1177 / 105960118100600404$

63. Gabutti I, Morandi F. HRM practices and organizational change: Evidence from Italian clinical directorates. Health Serv Manage Res. 2019;32(2):78-88. https://doi.org/10.1177/0951484818790213.

64. Kaplan HC, Brady PW, Dritz MC, et al. The influence of context on quality improvement success in health care: a systematic review of the literature. Milbank Q. 2010;88(4):500-59. https://doi.org/10.1111/j.1468-0009.2010. 00611.x.

\section{Publisher's Note}

Springer Nature remains neutral with regard to jurisdictional claims in published maps and institutional affiliations. 